\title{
Orexin A upregulates the protein expression of OX1R and enhances the proliferation of SGC-7901 gastric cancer cells through the ERK signaling pathway
}

\author{
YUANYUAN LIU ${ }^{1}$, YUYAN ZHAO ${ }^{1}$, SHUJING JU ${ }^{1}$ and LEI GUO ${ }^{2}$ \\ Departments of ${ }^{1}$ Endocrinology and ${ }^{2}$ Orthopedic Surgery, First Affiliated Hospital, \\ China Medical University, Shenyang, Liaoning 110001, P.R. China
}

Received July 27, 2014; Accepted November 25, 2014

DOI: $10.3892 /$ ijmm.2014.2038

\begin{abstract}
Orexins are hypothalamic peptides that regulate food intake, wakefulness, the reward system and energy metabolism. Recent studies have demonstrated the ability of orexins to promote a robust apoptosis and subsequent inhibition of cell growth in various types of cancer cells. The present study was conducted to investigate the effects of orexin A on the survival of human gastric cancer cells, SGC-7901, and the possible mechanisms. SGC-7901 cells were exposed to various concentrations of orexin A in vitro in the presence or absence of the orexin receptor 1 (OX1R) antagonist (SB334867), extracellular signal-regulated kinases 1 and 2 (ERK1/2) antagonist (U0126) or a combination of the two antagonists. The amount of cell proliferation, viability and apoptosis, caspase- 8 and caspases-9 activities, OX1R protein expression and ERK1/2 protein levels were determined. The expression of OX1R in SGC-7901 cells was observed. Orexin A $\left(10^{-10}\right.$ to $\left.10^{-6} \mathrm{M}\right)$ stimulated SGC-7901 cell proliferation and viability, reduced the pro-apoptotic activity of caspase- 9 and protected the cells from apoptosis in a dose-dependent manner. Additionally, ERK1/2 phosphorylation was stimulated by orexin A $\left(10^{-10}\right.$ to $\left.10^{-6} \mathrm{M}\right)$. However, the OX1R antagonist SB334867 $\left(10^{-6} \mathrm{M}\right)$, ERK1/2 antagonist U0126 $(30 \mu \mathrm{M})$ or the combination of antagonists blocked the effects of orexin A to a certain extent. These results suggest that stimulation of OX1R induces the growth of SGC-7901 gastric cancer cells through activation of ERK1/2 signaling pathway. These findings add a new dimension to the biological activities of orexin, which may have important implications in health and disease, in particular gastric cancer.
\end{abstract}

Correspondence to: Professor Yuyan Zhao, Department of Endocrinology, First Affiliated Hospital, China Medical University, 155 Nanjing North Street, Shenyang, Liaoning 110001, P.R. China E-mail: g572@sina.com

Key words: orexin A, orexin receptor 1, proliferation, apoptosis, extracellular signal-regulated kinase signaling pathway

\section{Introduction}

Orexin A and orexin B (also called hypocretins) are evolutionarily-conserved neuropeptides that were initially discovered by subtractive cDNA cloning (1) and/or orphan receptor technologies (2). The two peptides originate from the same precursor synthesized by hypothalamic neurons $(1,2)$. They trigger diverse facets of physiology via two subtypes of G-protein coupled receptors, orexin receptor 1 (OX1R) and OX2R (3). In addition to the hypothalamus, functions of orexins have also been described in peripheral tissues, including adrenal gland, pancreas, adipose tissue, gastrointestinal tract and testis (4-8). They control a number of important physiological processes, such as food intake, sleep-wake cycle, drug addition, energy metabolism, gastrointestinal function, neuroendocrine regulation and cardiovascular modulation $(5,9,10)$.

Apart from its roles in regulating central and peripheral actions, orexins have been previously highlighted in cancer cells (11-14). Orexins, acting at OX1R or OX2R, result in strong apoptosis and a decrease of cell growth in diverse cancer cell lines, including human colon cancer cells $(11,12)$, human neuroblastoma cells (11), rat pancreatic tumor cells (13) and rat C6 glioma cells (14). Studies have shown that orexins promote strong apoptosis in human colon cancer cells through OX1R by inducing the release of cytochrome $c$ from mitochondria and activation of caspase-3/7 (12). Orexin A can induce apoptosis via $\mathrm{OX} 2 \mathrm{R}$ in rat pancreatic tumor cells involving the caspase-3 and caspase-9 pathway (13). A study also found that orexin A induces p38/mitogen-activated protein kinase (MAPK)- and caspase-dependent cell death in rat C6 glioma cells (14).

The finding that orexin signaling is capable of inducing apoptosis in cancer cells, however, is not applicable to all cell lines. The signaling pathways induced by orexins may be a possible factor determining their effects on cell survival. The complexity of orexin physiology and pathology is reflected in the complicated downstream MAPK cascades being activated, particularly the extracellular signal-regulated kinase (ERK) and p38 (9). Previous studies have shown involvement of orexin A-induced ERK1/2 activation in the survival of Chinese hamster ovary (CHO) cells overexpressing OX1R (15). The ERK1/2-MAPK pathway, which is frequently activated in human cancers, may be conducive to increase cell 
proliferation and viability $(16,17)$. The phosphorylation of the ERK1/2-MAPK cascade can induce cell proliferation, and inhibition of ERK1/2 with selective inhibitors may lead to cell apoptosis in gastric cancer cells (18-20).

Although there is increasing interest in the biological actions of orexins on cancer cells, little information is available regarding the potential role of this peptide on gastric cancer cells. The present study aimed to investigate the expression of the orexin receptors in the human gastric carcinoma cell line, SGC-7901, and further examine whether orexin A induces OX1R and ERK1/2 signaling mediates its effects on the survival of SGC-7901 cells.

\section{Materials and methods}

Reagents. Orexin A was obtained from Sigma-Aldrich (St. Louis, MO, USA). RPMI 1640 medium and fetal bovine serum were purchased from Gibco (Grand Island, NY, USA). The ERK1/2 inhibitor, U0126, was purchased from Cell Signaling Technology (Beverly, MA, USA). OX1R-specific antagonist SB334867 was obtained from Tocris Bioscience (Minneapolis, MA, USA). Total/phospho-ERK1/2 polyclonal antibodies were obtained from Santa Cruz Biotechnology, Inc. (Santa Cruz, CA, USA). The OX1R and $\beta$-actin polyclonal antibodies were all obtained from Abcam (Cambridge, MA, USA).

Cell culture. Human gastric cancer cells SGC-7901 were obtained from the Type Culture Collection of the Chinese Academy of Sciences (Shanghai, China) and maintained in RPMI 1640 medium supplemented with 10\% fetal bovine serum, $50 \mu \mathrm{g} / \mathrm{ml}$ penicillin and $100 \mu \mathrm{g} / \mathrm{ml}$ streptomycin (Xianfeng, Shanghai, China). The cells were grown in a humidified atmosphere containing $5 \% \mathrm{CO}_{2}$ at $37^{\circ} \mathrm{C}$. Before the experiment, the cells were grown in petri dishes in a serum-free medium for $24 \mathrm{~h}$. The following day, the cells were treated with different concentrations of orexin A $\left(0,10^{-10}, 10^{-8}\right.$ and $\left.10^{-6} \mathrm{M}\right), 10^{-6} \mathrm{M}$

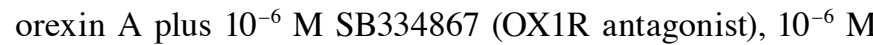
orexin A plus $30 \mu \mathrm{M}$ U0126 (ERK1/2 inhibitor), and $10^{-6} \mathrm{M}$ orexin A plus U0126 and SB334867 for $20 \mathrm{~min}$, respectively.

Cell proliferation. SGC-7901 cells were seeded ( $2 \times 10^{3}$ cells/well) in 96-well plates and cultured for $24 \mathrm{~h}$. To synchronize the cell cycles, cells were serum-deprived for $24 \mathrm{~h}$ and subsequently treated with test agents for an additional $24 \mathrm{~h}$. BrdU solution $\left(10^{-6} \mathrm{M}\right)$ was added and cells were incubated for $2.5 \mathrm{~h}$. The BrdU incorporation into the DNA was measured by the cell proliferation ELISA BrdU colorimetric kit (Roche Diagnostics, Penzberg, Germany).

Cell viability. SGC-7901 cells were seeded into( $2 \times 10^{3}$ cells/well) well plates and cultured for $24 \mathrm{~h}$. Following incubation in a serum-free RPMI 1640 supplemented with various concentrations $\left(0,10^{-10}, 10^{-8}\right.$ and $\left.10^{-6} \mathrm{M}\right)$ of orexin A or $10^{-6} \mathrm{M}$ orexin $\mathrm{A}$ with $10^{-6} \mathrm{M}$ OX1R antagonist SB334867 at $37^{\circ} \mathrm{C}$, SGC-7901 cell proliferation was determined by a colorimetric methyl thiazolyl tetrazolium cell proliferation and viability assay. A total of $50 \mu 13$-(4, 5-dimethylthiazol-2-yl)-2,5-diphenyltetrazolium bromide (MTT Sigma-Aldrich) cell proliferation assay solution was added to each well. After an additional $3 \mathrm{~h}$, the culture medium was removed and the formed formazan crystals were dissolved in $100 \mu$ l dimethyl sulfoxide. Optical density was measured by a plate reader (SpectraMax Plus ${ }^{384}$ microplate reader; Molecular Devices, Ismaning, Germany) at $570 \mathrm{~nm}$ and $650 \mathrm{~nm}$ (reference wave length). All the experiments were performed in triplicate. The absorbance $570 \mathrm{~nm}$ value of the control was used as a $100 \%$ standard and all the individual measurements were compared to this standard.

Annexin V/propidium iodide (PI) assays for apoptosis. For Annexin V/PI assays, cells were stained with Annexin V-fluorescein isothiocyanate (FITC) and PI, and evaluated for apoptosis by flow cytometry according to the manufacturer's instructions (BD Biosciences Pharmingen, San Diego, CA, USA). Cells were treated with different concentrations of orexin A in the absence of serum for $48 \mathrm{~h}$. Briefly, cells $\left(1 \times 10^{5}\right)$ were washed twice with phosphate-buffered saline, and stained with $5 \mu \mathrm{l}$ Annexin V-FITC and $10 \mu \mathrm{l}$ PI in $500 \mu \mathrm{l}$ binding buffer for $15 \mathrm{~min}$ at room temperature in the dark. Quantification of apoptosis was determined by counting the number of cells stained by FITC-labeled Annexin V. Cell apoptosis was detected using the Annexin V-FITC/PI apoptosis detection kit (BestBio, Shanghai, China) by fluorescence-activated cell sorting analysis. Early apoptotic cells were identified as PI negative and FITC Annexin V positive, while late apoptotic or dead cells were considered FITC Annexin V and PI positive.

Activity of caspase-8 and caspase-9 in SGC-7901 cells. SGC-7901 cells were cultured in a serum-free medium in 6 -well plates $\left(1.5 \times 10^{5}\right.$ cells/well). Caspase- 8 and caspase- 9 activities were assessed using Caspase- 8 and Caspase- 9 colorimetric assay kit (BioVision Inc., Headquarters, Milpitas, CA, USA), respectively.

Quantitative polymerase chain reaction ( $q P C R$ ). Total RNA was extracted from SGC-7901 cells using the TRIzol reagent (Life Technologies Co., Carlsbad, CA, USA). Following spectrophotometric quantification, $1 \mu \mathrm{g}$ total RNA was converted into cDNA using the PrimeScript ${ }^{\mathrm{TM}}$ RT reagent kit with gDNA Eraser (Takara Bio, Otsu, Japan) according to the manufacturer's instructions. cDNA aliquots corresponding to equal amounts of RNA were used for the quantification of mRNA by qPCR using the LightCycler 96 real-time quantitative PCR detection system (Roche, Indianapolis, IN, USA). The following specific primers were used: $O X 1 R$ forward, 5'-TGCGGCCAACCCTATCATCTA-3' and reverse, 5'-ACCGGCTCTGCAAGGACAA-3'; and $O X 2 R$ forward, 5'-ATCGCAGGGTATATCATCGTGTTC-3' and reverse, 5'-TGACTGTCCTCATGTGGTGGTTC-3'. As an internal control for reverse transcription (RT) and reaction efficiency, amplification of glyceraldehyde-3-phosphate dehydrogenase $(G A P D H)$ mRNA was carried out in parallel for each sample. The following specific primers were used: $G A P D H$ forward, 5'-GGCACAGTCAAGGCTGAGAATG-3' and reverse, 5'-ATGGTGGTGAAGACGCCAGTA-3'. The reaction system was $25 \mu \mathrm{l}$, including $2 \mu \mathrm{l}$ cDNA template, $2 \mu \mathrm{l}$ forward and reverse primers, 8.5 $\mu 1 \mathrm{RNase-free} \mathrm{ddH}_{2} \mathrm{O}$, and $12.5 \mu \mathrm{l} \mathrm{SYBR}{ }^{\circledR}$ Premix Ex Taq ${ }^{\mathrm{TM}}$ II (Takara). The PCR reactions were carried out using the following conditions: $95^{\circ} \mathrm{C}$ for $30 \mathrm{sec}$, and subsequently 40 cycles of $95^{\circ} \mathrm{C}$ for $5 \mathrm{sec}, 60^{\circ} \mathrm{C}$ for $30 \mathrm{sec}$ and $95^{\circ} \mathrm{C}$ for $15 \mathrm{sec}$. All the primers specific to $O X 1 R, O X 2 R$ and 
GAPDH were designed using Primer Premier 5.0 software (Premier Biosoft International, Palo Alto, CA, USA).

Protein preparations and western blot analysis. Total protein was extracted from SGC-7901 cells using radioimmunoprecipitation assay cell lysis reagent containing proteinase and phosphatase inhibitors (Solarbio, Beiijng, China). The cells remained in the medium on ice for 30 min with re-dispersion every $5 \mathrm{~min}$. Cell lysates were centrifuged at $12,000 \mathrm{x} \mathrm{g}$ for $10 \mathrm{~min}$ at $4^{\circ} \mathrm{C}$, and the protein concentrations of the supernatants were determined using the bicinchoninic acid protein assay reagent kit (Beyotime Institute of Biotechnology, Shanghai, China). The supernatants containing total protein were mixed with a corresponding volume of 5X SDS loading buffer and were subsequently denatured by boiling for $10 \mathrm{~min}$. Samples were separated by SDS polyacrylamide gel electropheresis using $5 \%$ stacking and $12 \%$ separating gels. Subsequently, the samples were transferred onto polyvinylidene difluoride membranes $(0.2 \mu \mathrm{m}$, Immobilon-P; Millipore, Billerica, MA, USA) at $60 \mathrm{~V}$ for $2.5 \mathrm{~h}$. After being blocked with skimmed dry milk for $2 \mathrm{~h}$ at room temperature, the membranes were washed three times with Tris-buffered saline with Tween 20 (TBST) for $30 \mathrm{~min}$. The samples were incubated overnight at $4^{\circ} \mathrm{C}$ with the appropriate primary antibody. The primary antibodies and dilutions used were as follows: Rabbit anti-human OX1R (cat. no. Ab68718; 1:250), rabbit anti-human ERK1/2 (cat. no. sc-292838; 1:1,000), rabbit anti-human phospho-ERK1/2 (cat. no. sc-101760; 1:1,000) and rabbit anti-human $\beta$-actin (cat. no. Ab8337; 1:1,000). The membranes were washed and incubated at room temperature for $1.5 \mathrm{~h}$ with the secondary goat anti-rabbit immunoglobulin $\mathrm{G}$ $(\mathrm{H}+\mathrm{L})$ antibody (Beyotime, cat. no. A0208; 1:2,000) conjugated with horseradish peroxidase, and were washed three times with TBST for $30 \mathrm{~min}$. The membranes were subjected to enhanced chemiluminescence (ECL) using an ECL detection kit (Beyotime) and quantified using Quantity One software (Bio-Rad Laboratories Inc., Hercules, CA, USA).

Statistical analysis. All the data are expressed as the means \pm standard error of the mean and differences between the means were analyzed by one-way analysis of variance. $\mathrm{P}<0.05$ was considered to indicate a statistically significant difference. Statistical analysis was performed using the SPSS 15.0 software package (SPSS Inc., Chicago, IL, USA).

\section{Results}

Detection of OXIR expression in SGC-7901 cells. qPCR tests showed that $O X 1 R$ mRNA was expressed in SGC-7901 cells (Fig. 1A). However, $O X 2 R$ mRNA was not detectable under the same conditions (data not shown). OXIR mRNA and protein levels were significantly increased in response to orexin $\mathrm{A}\left(10^{-10}\right.$, $10^{-8}$ and $\left.10^{-6} \mathrm{M}\right)$ treatment compared to the untreated control group. The observed effects were concentration-dependent, with $10^{-6} \mathrm{M}$ orexin A being the most potent (Fig. 1A and B). However, these effects were blocked with $10^{-6} \mathrm{M}$ SB334867, a specific OX1R antagonist (Fig. 1B). These results suggested that orexin A increased OXIR mRNA and protein levels in SGC-7901 cells.

Effects of orexin A on proliferation and viability of SGC-7901 cells. To characterize the effects of orexin A on the proliferation
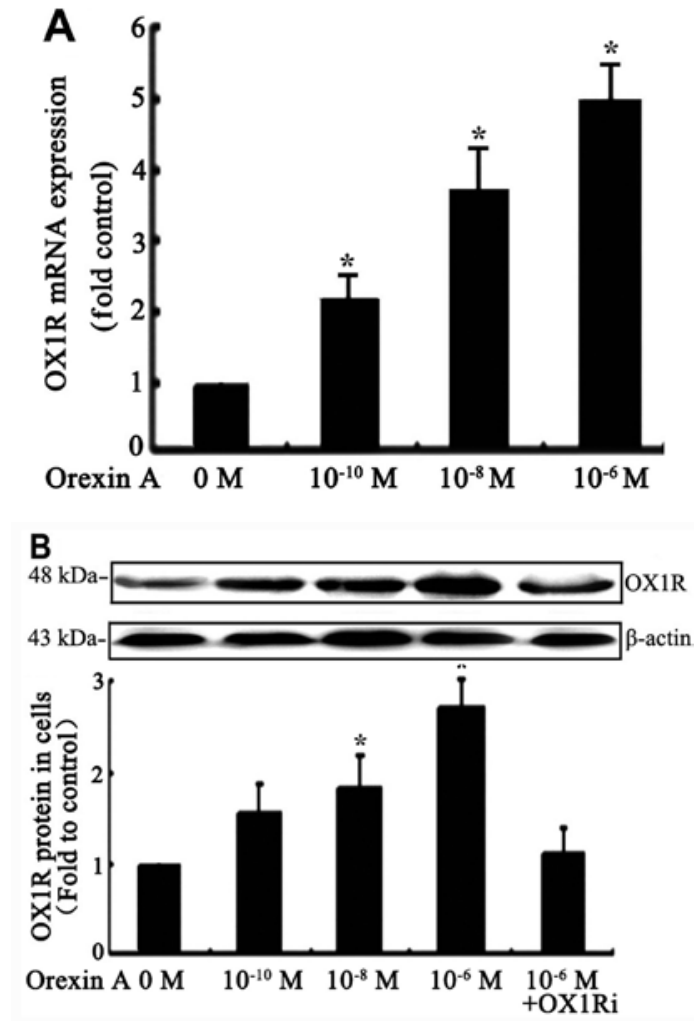

Figure 1. Expression of orexin receptor $1(O X 1 R)$ in mRNA and protein activation in SGC-7901 cells. Cells were exposed to orexin A at concentrations of $0,10^{-10}, 10^{-8}$ and $10^{-6} \mathrm{M}$ for $24 \mathrm{~h}$. Another treatment group consisted of $10^{-6} \mathrm{M}$ orexin A in the presence of the OX1R antagonist SB334867 (10 ${ }^{-6} \mathrm{M}$ OX1Ri). The expression of (A) $O X 1 R$ mRNA and (B) protein was measured via reverse transcription (RT)-PCR and western blot analysis, respectively. Data are presented as mean \pm standard error of the mean based on triplicate determinations from a representative experiment. ${ }^{*} \mathrm{P}<0.05$ compared to control.

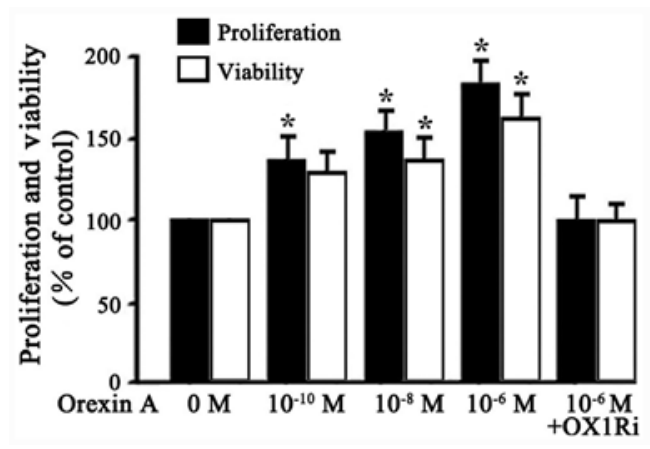

Figure 2. Effects of orexin A on the proliferation and viability of SGC-7901 cells. Cells were exposed to orexin A at concentrations of $0,10^{-10}, 10^{-8}$ and $10^{-6} \mathrm{M}$ for $24 \mathrm{~h}$. Another treatment group consisted of $10^{-6} \mathrm{M}$ orexin $\mathrm{A}$ in the presence of the OX1R antagonist SB334867 $\left(10^{-6} \mathrm{M}\right.$ OX1Ri). Proliferation and viability were determined by the BrdU assays and the MTT test, respectively. Data are presented as mean \pm standard error of the mean based on triplicate determinations from a representative experiment. ${ }^{*} \mathrm{P}<0.05$ compared to control.

and viability of SGC-7901 cells, viable cells were treated with different concentrations of orexin $\mathrm{A}\left(0,10^{-10}, 10^{-8}\right.$ and $\left.10^{-6} \mathrm{M}\right)$ or orexin $\mathrm{A}\left(10^{-6} \mathrm{M}\right)$ with OX1R antagonist, SB334867 $\left(10^{-6} \mathrm{M}\right)$. Results showed that orexin $\mathrm{A}\left(10^{-10}, 10^{-8}\right.$ and $\left.10^{-6} \mathrm{M}\right)$ dose-dependently improved the proliferation and viability of SGC-7901 cells (Fig. 2). Stimulation by $10^{-6} \mathrm{M}$ orexin A increased proliferation and viability of the cells by 80 and $60 \%$ 

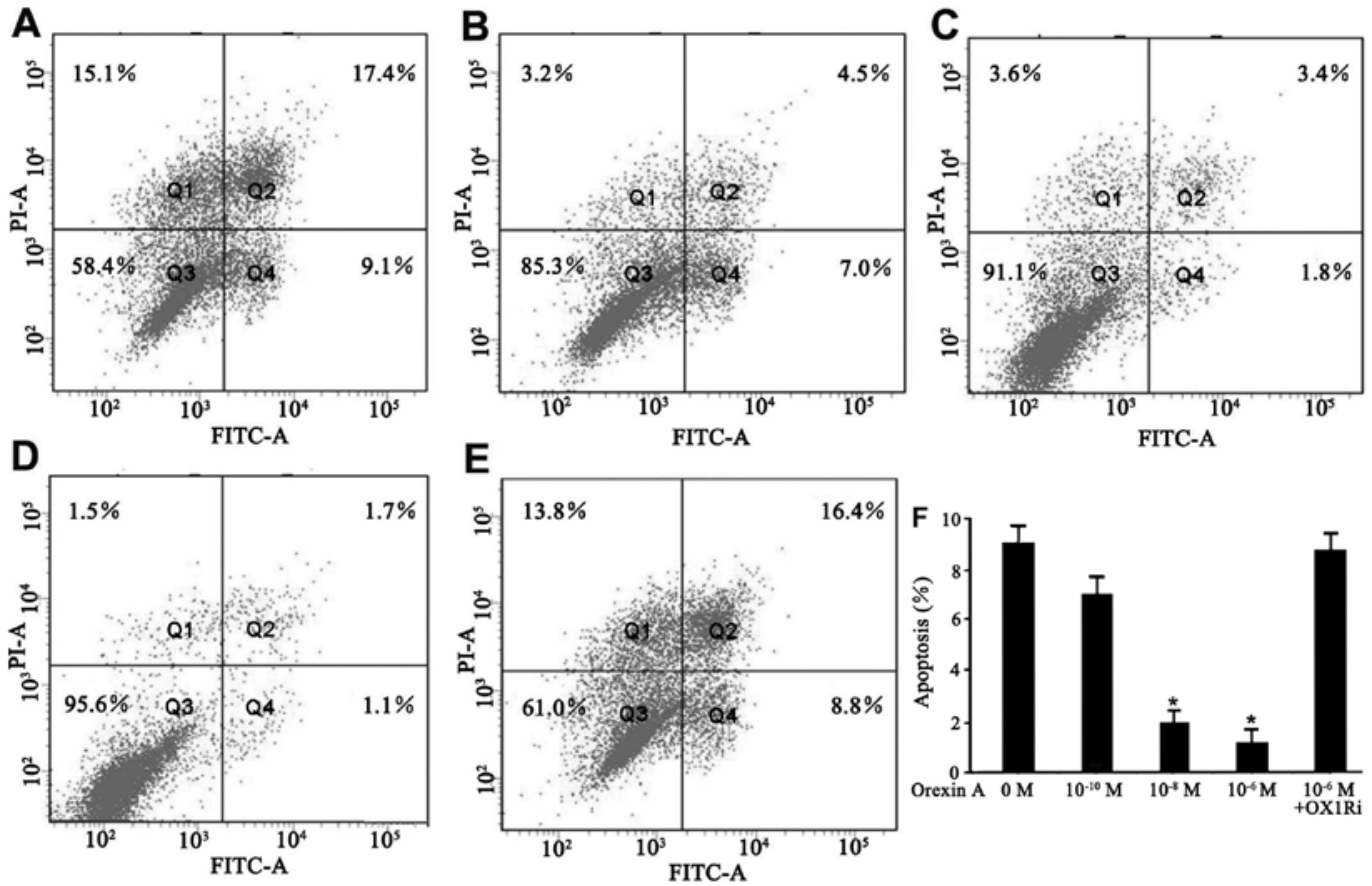

Figure 3. Orexin A protects SGC-7901 cells against serum deprivation-induced apoptosis. Cells were exposed to orexin A at concentrations of (A) 0 , (B) $10^{-10}$, (C) $10^{-8}$ and (D) $10^{-6} \mathrm{M}$ for $48 \mathrm{~h}$, or cells treated with $10^{-6} \mathrm{M}$ orexin $\mathrm{A}$ in the presence of the (E) OX1R antagonist SB334867 (10-6 M OX1Ri) for $48 \mathrm{~h}$. Apoptosis was assessed with flow cytometry using Annexin V-fluorescein isothiocyanate (FITC) and propidium iodide (PI). Intensity of PI staining (y-axis) is plotted versus FITC intensity (x-axes). In all five plots, viable cells are observed in the left lower quadrant (FITC-/PI); early apoptotic cells in the right lower quadrant $\left(\mathrm{FITC}^{+} / \mathrm{PI}\right)$; late apoptotic cells in the right upper quadrant $\left(\mathrm{FITC}^{+} / \mathrm{PI}^{+}\right)$; and necrotic cells in the left upper quadrant $\left(\mathrm{FITC}^{-} / \mathrm{PI}^{+}\right)$. (F) The percentage of early apoptotic cells in the different groups are shown. Data are presented as mean \pm standard error of the mean based on triplicate determinations from a representative experiment. ${ }^{*} \mathrm{P}<0.05$ compared to control.

over basal, respectively (Fig. 2). These effects were blocked by SB334867 $\left(10^{-6} \mathrm{M}\right)$ (Fig. 2). These results indicated that orexin A, acting at $\mathrm{OX} 1 \mathrm{R}$, promoted proliferation and viability of SGC-7901 cells.

Orexin A protects SGC-7901 cells from apoptosis. The effect of orexin A on apoptosis of SGC-7901 cells in a serum-deprived culture condition was evaluated by flow cytometry for Annexin V/PI staining. The cells underwent apoptotic death in the absence of serum for $48 \mathrm{~h}$ (Fig. 3A). However, addition of orexin $\mathrm{A}\left(10^{-10}, 10^{-8}\right.$ and $\left.10^{-6} \mathrm{M}\right)$ dose-dependently decreased the number of dead cells. The percentage of early apoptotic cells $\left(\mathrm{Annexin} \mathrm{V}^{+} / \mathrm{PI}\right)$ was $9.1,7.0,1.8$ and $1.1 \%$ in response to the vehicle, $10^{-10}, 10^{-8}$, and $10^{-6} \mathrm{M}$ orexin $\mathrm{A}$, respectively, for $48 \mathrm{~h}$ (Fig. 3A-D). Orexin A $\left(10^{-6} \mathrm{M}\right)$ did not protect the cells against apoptosis in the presence of SB334867 (Fig. 3E and F). These results showed that orexin A effectively inhibited serum starvation-induced apoptosis in SGC-7901 cells.

Effect of orexin A on ERK1/2 activation in SGC-7901 cells. To elucidate the molecular mechanism responsible for the effects observed with orexin A treatment, the effect of orexin A was investigated on the ERK1/2-MAPK pathway, which is frequently activated in human cancers and contributed to increase cell proliferation and survival. The results showed that no significant change was observed in total protein expression of ERK1/2 (Fig. 4). The phosphorylation level of ERK1/2, however, was increased in response to orexin A $\left(10^{-10}, 10^{-8}\right.$ and $\left.10^{-6} \mathrm{M}\right)$ treatment for $20 \mathrm{~min}$ in a dose-dependent manner (Fig. 4). Orexin A $\left(10^{-6} \mathrm{M}\right)$ stimulated ERK1/2

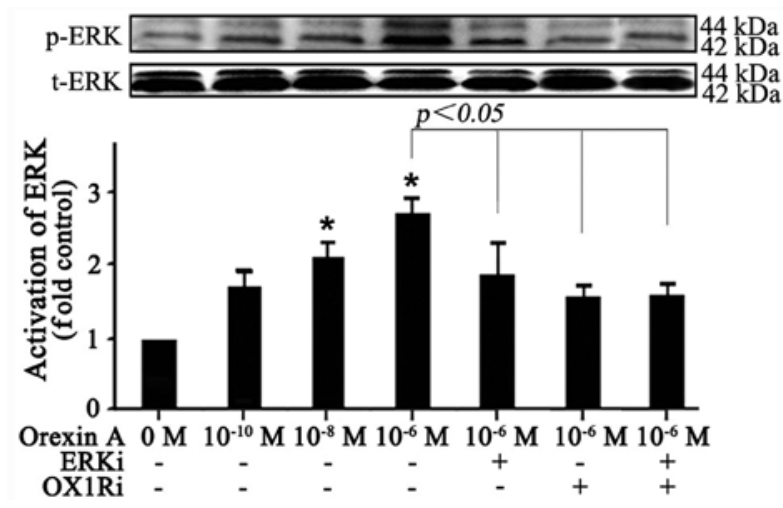

Figure 4. Effects of orexin A on extracellular signal-regulated kinase (ERK)1/2 activation in SGC-7901 cells. Cells were treated with orexin A at concentrations of $0,10^{-10}, 10^{-8}$ and $10^{-6} \mathrm{M}$ for $20 \mathrm{~min}$ in the presence or absence of U0126 (30 $\mu \mathrm{M}$ ERKi), SB334867 $\left(10^{-6} \mathrm{M}\right.$ OX1Ri) or the combination of the two antagonists. The phosphorylation of ERK1/2 (p-ERK1/2) (corresponds to 42 and $44 \mathrm{kDa}$ ) was normalized against the total protein (t-ERK1/2) activation. The t-ERK1/2 protein expression was used as an internal control for equal protein loading. Protein activation was measured by western blot analysis. Data are presented as mean \pm standard error of the mean based on triplicate determinations from a representative experiment. ${ }^{*} \mathrm{P}<0.05$ compared to control.

phosphorylation by 2.7-fold over basal (Fig. 4). Additionally, the $30 \mu \mathrm{M}$ ERK1/2 antagonist U0126, $10^{-6} \mathrm{M}$ OX1R antagonist SB334867 or the combination of the two antagonists prevented orexin A $\left(10^{-6} \mathrm{M}\right)$ in stimulating ERK1/2 phosphorylation (Fig. 4). Thus, the data suggested that orexin A treatment resulted in the activation of ERK1/2, which may participate in orexin A-induced cell growth in SGC-7901 cells. 


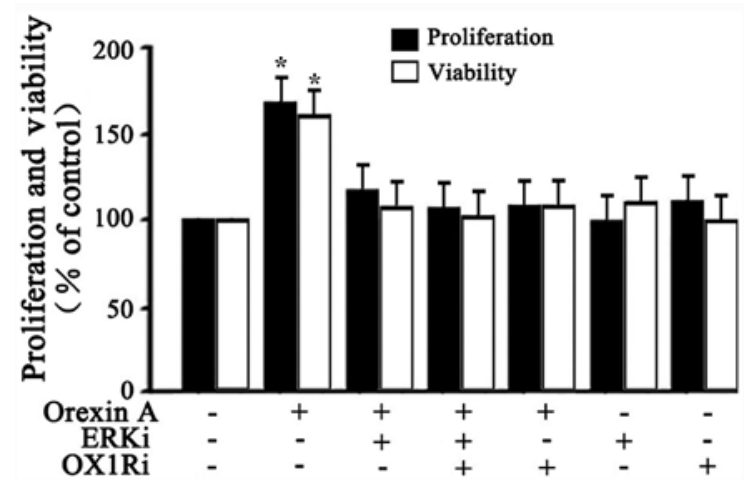

Figure 5. Effects of orexin A on the proliferation and viability of SGC-7901 cells via stimulation of extracellular signal-regulated kinase (ERK)1/2 signaling pathway. Cells were treated with or without orexin A $\left(10^{-6} \mathrm{M}\right)$ for $24 \mathrm{~h}$ in the presence or absence of U0126 (30 $\mu \mathrm{M}$ ERKi), SB334867 $\left(10^{-6} \mathrm{M}\right.$ OX1Ri), or a combination of the two antagonists. Proliferation and viability were determined by the BrdU assay and MTT test, respectively. Data are presented as mean \pm standard error of the mean based on triplicate determinations from a representative experiment. " $\mathrm{P}<0.05$ compared to control.

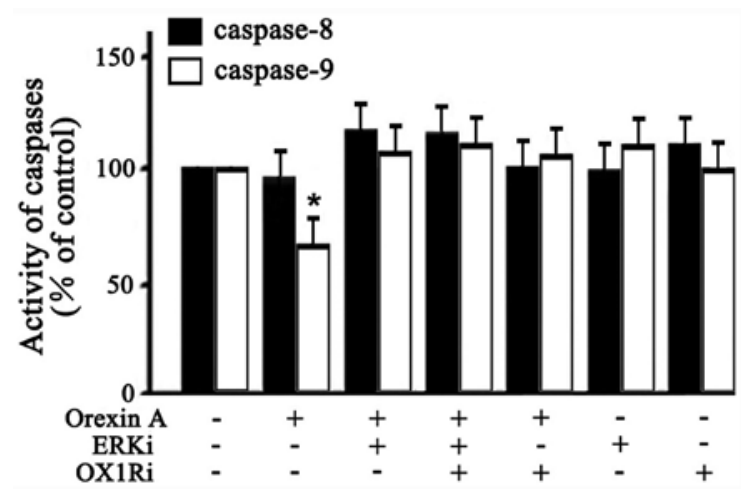

Figure 6. Effects of orexin A on caspase- 8 and caspase- 9 activities in SGC-7901 cells. Cells were treated with or without orexin A $\left(10^{-6} \mathrm{M}\right)$ for $24 \mathrm{~h}$ in the presence or absence of U0126 (30 $\mu \mathrm{M}$ ERKi), SB334867 $\left(10^{-6} \mathrm{M}\right.$ OX1Ri) or a combination of the two antagonists. Caspase- 8 and caspase- 9 activities were assessed using the caspase- 8 and caspase- 9 colorimetric assay kits, respectively. Data are presented as mean \pm standard error of the mean based on triplicate determinations from a representative experiment. ${ }^{*} \mathrm{P}<0.05$ compared to control.

Effects of orexin A on proliferation and viability of SGC-7901 cells via ERK1/2 signaling pathway. Whether the activation of ERK1/2 signaling was responsible for orexin A-induced cell proliferation and viability was further explored. BrdU analysis and MTT analysis were employed to test cell survival. As shown in Fig. 5, 10 $0^{-6} \mathrm{M}$ orexin A stimulation significantly increased the proliferation and viability of SGC-7901 cells compared to the control. However, these effects were inhibited with U0126 (30 $\mu \mathrm{M}$ ERKi) co treatment, SB334867 $\left(10^{-6} \mathrm{M}\right.$ OX1Ri) or the combination of the two antagonists (Fig. 5). These data suggested that ERK1/2 participated in orexin A-induced stimulation of proliferation and viability in SGC-7901 cells.

Activities of caspase- 8 and caspase-9 in SGC-7901 cells. The caspase family proteins are critical enzymes that execute apoptosis. To determine whether the orexin A-induced anti-apoptotic effect was through extrinsic or intrinsic mechanisms, caspase- 8 and -9 activities was examined. As shown in Fig. $6,10^{-6} \mathrm{M}$ orexin A treatment caused a significant attenuation in caspase- 9 activity ( $33 \%$ below the control). However, caspase- 8 activity in cells was not significantly changed (Fig. 6). Additionally, the effect of orexin A in caspase-9 activity was inhibited in the presence of U0126 (30 $\mu \mathrm{M}$ ERKi), SB334867 (10-6 M OX1Ri), or the combination of these two antagonists (Fig. 6). These findings suggested that orexin A protected SGC-7901 cells against apoptosis through blocking the activation of the pro-apoptotic executor protease caspase-9 via ERK1/2.

\section{Discussion}

To the best of our knowledge, the present study demonstrated for the first time that $O X 1 R$ was expressed in human gastric cancer cells SGC-7901. These results showed that orexin A promoted proliferation and viability, attenuated caspase-9 activity and protected against apoptotic cell death of SGC-7901 cells. In addition, the pro-survival and anti-apoptotic properties of orexin A in SGC-7901 cells were associated, at least in part, with activation of ERK1/2-MAPK pathway.

As an important group of $\mathrm{G}$ protein-coupled receptors, orexin receptors have been identified as expressed in a number of cancer cell lines. The cell lines expressing OX1R included human colon carcinoma cells HT29-D4, SW480, LoVo, Caco-2 and human neuroblastoma SK-N-MC (11). OX2R mRNA was expressed in rat pancreatic acinar tumor line AR42J (13). OX1R and OX2R were detected in rat C6 glioma cells (14). These cell lines exhibited decreased cell division and increased cell death upon orexin exposure. Clinically, recent evidence indicated the involvement of epigenetic silencing of OX2R in endometrial endometrioid carcinoma (21). Compared to normal prostates, expression levels of $O X 2 R$ were markedly elevated in adenomatous prostates (22). All these studies point to orexin receptors as novel therapeutic target in cancer chemotherapy. In the present study, $O X 1 R$ was expression was confirmed in SGC-7901 gastric cancer cells while $O X 2 R$ mRNA was not detectable under the same conditions. Orexin A dose-dependently upregulated the expression of OXIR in SGC-7901 cells. Instead of causing apoptosis, orexin A exerted survival-promoting activity through $O X 1 R$ in SGC-7901 cells, which coincided with the effects observed in human adrenocortical adenomas (23) and rat adrenocortical cells (24). Thus, orexins may act as a regulatory peptide taking part in cell proliferation and apoptosis.

MAPK signaling pathways regulate multiple cellular programs including differentiation, gene expression and proliferation (25). ERK1/2 is a main member of the MAPK family and has been well-documented to associate with cell proliferation and survival $(26,27)$. Several key growth factors and pro-oncogenes promote cell growth by activating this signaling cascade (28-31). Previous evidence indicates that orexins can govern diverse physiological and pharmacological processes by regulating ERK1/2 activation (32-34). In 3T3-L1 preadipocytes, orexin A stimulated cell proliferation and viability, and protected the cells from apoptosis via ERK1/2 signaling pathway (35). Consistent with these observations, activation of the ERK1/2 in response to orexin A treatment was also observed in the present study. Furthermore, orexin A-induced cell proliferation and viability was significantly reduced by 
co-treatment with the ERK1/2 antagonist, indicating that the growth and proliferation of SGC-7901 cells possibly occur through the ERK1/2 signaling pathway.

Apoptotic signaling is typically mediated by two main apoptotic pathways, which have been identified as the death receptor-mediated caspase- 8 extrinsic pathway and the mitochondria-mediated caspase- 9 intrinsic pathway $(36,37)$. Caspase-3, characterized as the downstream executor, cleaves cellular target proteins leading to cell death. Orexins have been reported to suppress cell growth by inducing apoptosis through activation of caspase- 3 and caspase- 9 in rat pancreatic tumor cells and $\mathrm{CHO}$ cells (13). Conversely, orexins can promote growth of neuronal cells via inhibition of caspase-3 activity (38). In the present study, orexin A treatment was show to markedly inhibit serum starvation-induced apoptosis of SGC-7901 cells, which was further confirmed by attenuated activity of caspase-9. However, orexin A had no effect on the activity of caspase- 8 under the same conditions, suggesting that orexin A can inhibit the intrinsic apoptotic pathway to protect SGC-7901 cells against apoptosis. Furthermore, activation of ERK signaling is known to inhibit apoptosis by inactivating the pro-apoptotic proteins (39-41). In the present study, orexin A treatment failed to inhibit caspase- 9 activity in the presence of the ERK1/2 antagonist. Thus, it can be hypothesized that the activation of ERK1/2 by orexin A treatment resulted in the attenuation of caspase- 9 activity and subsequent inhibition of apoptosis in SGC-7901 cells.

Although studies have demonstrated the ability of orexins to induce apoptosis and subsequently inhibit cell growth in diverse cancer cells, the effect of orexin signaling appears to be different in different types of cells. Contrary to expectation, orexin A stimulated the proliferation and viability of the gastric cancer cells, SGC-7901, reduced pro-apoptotic activity of caspase- 9 and protected the cells from apoptosis. This is similar to a previous study performed on human adrenocortical adenomas that express the two orexin receptors, which demonstrated that orexins stimulated in vitro growth of the tumor cells (23). Orexin A also increased cell viability and inhibited the activities of caspase- 3 and caspase- 7 to protect against apoptosis in immortalized primary embryonic rat hypothalamic R7 cells (42). The mechanisms underlying dual functions of orexins in the context of cell growth and death require investigation. Why the peptides raise proliferative activity in some cells, while in other cells they induce apoptosis remains to be solved. One possible explanation for this may be due to the pathways induced by orexins. Studies performed on $\mathrm{CHO}$ cells and human embryonic kidney (HEK-293) stably expressing human OX1R and OX2R have demonstrated that orexins can exert the opposite effects on cell survival through activation of the classical MAPK pathways. The ERK1/2 pathway was central for cell growth, whereas $\mathrm{p} 38$ was important for cell death $(15,43)$. In accordance with these observations, the orexin A-induced increase in proliferation and viability of 3T3-L1 preadipocytes was blocked by U0126, an ERK1/2 inhibitor (35), whereas the suppressive action of orexin A on survival of rat C6 glioma cells was blocked by SB202190, a specific p38 MAPK inhibitor (14). Another possible explanation may be the different intrinsic sensitivity of cells to the action of cytochrome $c$. In the intrinsic apoptotic pathway, cytochrome $c$ releases from mitochondria to cytosol, and binds to Apaf-1 resulting in formation of the apoptosome (44). The levels of Apaf-1 may be different depending on cell type and growth stage (45). However, the understanding of the function and mechanism of orexin signaling in cancer remains at an early stage and further studies are required to clarify this novel field.

In conclusion, the present study demonstrates for the first time that a physiologically present neuropeptide, orexin A, has direct pro-survival and anti-apoptotic effects presumably through $O X 1 R$ being expressed in SGC-7901 gastric cancer cells through the ERK1/2 signaling pathway. Overall, these findings add a new dimension to the biological activities of this neuropeptide on gastric cancer cells, which may have important implications in health and disease.

\section{Acknowledgements}

The authors are thankful to the China Medical University Affiliated Hospital Laboratory Center for kindly providing the equipment required. The present study was supported by the National Natural Science Foundation of China (grant nos. 30872724, 81071460 and 81271996) and the Natural Science Foundation of Liaoning Province (grant no. 201202292).

\section{References}

1. De Lecea L, Kilduff TS, Peyron C, et al: The hypocretins: hypothalamus-specific peptides with neuroexcitatory activity. Proc Natl Acad Sci USA 95: 322-327, 1998.

2. Sakurai T,Amemiya A, Ishii M,et al: Orexins and orexin receptors: a family of hypothalamic neuropeptides and $\mathrm{G}$ protein-coupled receptors that regulate feeding behavior. Cell 92: 573-585, 1998.

3. Karteris E and Randeva HS: Orexin receptors and G-protein coupling: evidence for another 'promiscuous' seven transmembrane domain receptor. J Pharmacol Sci 93: 126-128, 2003.

4. Nakabayashi M, Suzuki T, Takahashi K, et al: Orexin-A expression in human peripheral tissues. Mol Cell Endocrinol 205: 43-50, 2003.

5. Korczynski W, Ceregrzyn M, Matyjek R, et al: Central and local (enteric) action of orexins. J Physiol Pharmacol 57: 17-42, 2006.

6. Okumura T and Nozu T: Role of brain orexin in the pathophysiology of functional gastrointestinal disorders. J Gastroenterol Hepatol 26: 61-66, 2011.

7. Kagerer S, M and Jöhren O: Interactions of orexins/hypocretins with adrenocortical functions. Acta Physiol 198: 361-371, 2010.

8. Jöhren O, Neidert S, J, Kummer M, et al: Prepro-orexin and orexin receptor mRNAs are differentially expressed in peripheral tissues of male and female rats. Endocrinology 142: 3324-3331, 2001.

9. Xu TR, Yang Y, Ward R, Gao L and Liu Y: Orexin receptors: multi-functional therapeutic targets for sleeping disorders, eating disorders, drug addiction, cancers and other physiological disorders. Cell Signal 25: 2413-2423, 2013.

10. Heinonen MV, Purhonen AK, Makela KA and Herzig KH: Functions of orexins in peripheral tissues. Acta Physiologica 192: 471-485, 2008.

11. Rouet-Benzineb P, Rouyer-Fessard C, Jarry A, et al: Orexins acting at native $\mathrm{OX} 1$ receptor in colon cancer and neuroblastoma cells or at recombinant OX1 receptor suppress cell growth by inducing apoptosis. J Biol Chem 279: 45875-45886, 2004.

12. Voisin T, El Firar A, Fasseu M, et al: Aberrant expression of OX1 receptors for orexins in colon cancers and liver metastases: an openable gate to apoptosis. Cancer Res 71: 3341-3351, 2011.

13. Voisin T, El Firar A, Avondo V, et al: Orexin-induced apoptosis: the key role of the seven-transmembrane domain orexin type 2 receptor. Endocrinology 147: 4977-4984, 2006.

14. Bieganska K, Sokolowska P, Johren O and Zawilska JB: Orexin A suppresses the growth of rat C6 glioma cells via a caspase-dependent mechanism. J Mol Neurosci 48: 706-712, 2012. 
15. Ammoun S, Lindholm D, Wootz H, et al: G-protein-coupled OX1 orexin/hcrtr-1 hypocretin receptors induce caspase-dependent and-independent cell death through p38 mitogen-/stress-activated protein kinase. J Biol Chem 281: 834-842, 2006.

16. Roberts PJ and Der CJ: Targeting the Raf-MEK-ERK mitogen-activated protein kinase cascade for the treatment of cancer. Oncogene 26: 3291-3310, 2007.

17. Hong SK, Yoon S, Moelling C, et al: Noncatalytic function of ERK1/2 can promote Raf/MEK/ERK-mediated growth arrest signaling. J Biol Chem 284: 33006-33018, 2009.

18. Tian PY and Fan XM: The proliferative effects of ghrelin on human gastric cancer AGS cells. J Dig Dis 13: 453-458, 2012.

19. Qian C, Yao J, Wang J, et al: ERK1/2 inhibition enhances apoptosis induced by JAK2 silencing in human gastric cancer SGC7901 cells. Mol Cell Biochem 387: 159-170, 2014.

20. Wu S, Lao XY, Sun TT, et al: Knockdown of ZFX inhibits gastric cancer cell growth in vitro and in vivo via down-regulating the ERK-MAPK pathway. Cancer Lett 337: 293-300, 2013.

21. Dehan P, Canon C, Trooskens G, et al: Expression of type 2 orexin receptor in human endometrium and its epigenetic silencing in endometrial cancer. J Clin Endocr Metab 98: 1549-1557, 2013.

22. Malendowicz W, Szyszka M, Ziolkowska A, et al: Elevated expression of orexin receptor 2 (HCRTR2) in benign prostatic hyperplasia is accompanied by lowered serum orexin A concentrations. Int J Mol Med 27: 377-383, 2011.

23. Spinazzi R, Rucinski M, Neri G, et al: Preproorexin and orexin receptors are expressed in cortisol-secreting adrenocortical adenomas, and orexins stimulate in vitro cortisol secretion and growth of tumor cells. J Clin Endocr Metab 90: 3544-3549, 2005

24. Spinazzi R, Ziolkowska A, Neri G, et al: Orexins modulate the growth of cultured rat adrenocortical cells, acting through type 1 and type 2 receptors coupled to the MAPK p42/p44-and p38-dependent cascades. Int J Mol Med 15: 847-852, 2005.

25. Raman M, Chen W and Cobb MH: Differential regulation and properties of MAPKs. Oncogene 26: 3100-3112, 2007.

26. Ballif BA and Blenis J: Molecular mechanisms mediating mammalian mitogen-activated protein kinase (MAPK) kinase (MEK)-MAPK cell survival signals. Cell Growth Differ 12: 397-408, 2001

27. Junttila MR, Li S-P and Westermarck J: Phosphatase-mediated crosstalk between MAPK signaling pathways in the regulation of cell survival. FASEB J 22: 954-965, 2008.

28. Yan L, Gu H, Li J, et al: RKIP and 14-3-3e exert an opposite effect on human gastric cancer cells SGC7901 by regulating the ERK/MAPK pathway differently. Dig Dis Sci 58: 389-396, 2013

29. Santarpia L, Lippman SM and El-Naggar AK: Targeting the MAPK-RAS-RAF signaling pathway in cancer therapy. Expert Opin Ther Targets 16: 103-119, 2012.

30. Fang JY and Richardson BC: The MAPK signaling pathways and colorectal cancer. Lancet Oncol 6: 322-327, 2005.
31. Kadowaki Y, Ishihara S, Miyaoka Y, et al: Reg protein is overexpressed in gastric cancer cells, where it activates a signal transduction pathway that converges on ERK1/2 to stimulate growth. FEBS Lett 530: 59-64, 2002.

32. Kim MK, Park HJ, Kim SR, et al: Angiogenic role of orexin-A via the activation of extracellular signal-regulated kinase in endothelial cells. Biochem Biophys Res Commun 403: 59-65, 2010.

33. Ramanjaneya M, Conner AC, Chen J, et al: Orexin-stimulated MAP kinase cascades are activated through multiple G-protein signaling pathways in human $\mathrm{H} 295 \mathrm{R}$ adrenocortical cells: diverse roles for orexins A and B. J Endocrinol 202: 249-261, 2009.

34. Gorojankina T, Grébert D, Salesse R, et al: Study of orexins signal transduction pathways in rat olfactory mucosa and in olfactory sensory neurons-derived cell line Odora: multiple orexin signaling pathways. Regul Pept 141: 73-85, 2007.

35. Skrzypski M, Kaczmarek P, Le TT, et al: Effects of orexin A on proliferation, survival, apoptosis and differentiation of 3T3-L1 preadipocytes into mature adipocytes. FEBS Lett 586: 4157-4164, 2012

36. Igney FH and Krammer PH: Death and anti-death: tumour resistance to apoptosis. Nat Rev Cancer 2: 277-288, 2002.

37. $\mathrm{Hu} \mathrm{W}$ and Kavanagh JJ: Anticancer therapy targeting the apoptotic pathway. Lancet Oncol 4: 721-729, 2003.

38. Sokołowska P, Urbańska A, Namiecińska M, et al: Orexins promote survival of rat cortical neurons. Neurosci Lett 506: 303-306, 2012.

39. Boucher MJ, Duchesne C, Lainé J, et al: cAMP protection of pancreatic cancer cells against apoptosis induced by ERK inhibition. Biochem Biophys Res Commun 285: 207-216, 2001.

40. Martin MC, Allan LA, Mancini EJ, et al: The docking interaction of caspase-9 with ERK2 provides a mechanism for the selective inhibitory phosphorylation of caspase- 9 at threonine 125. J Biol Chem 283: 3854-3865, 2008

41. Allan LA, Morrice N, Brady S, et al: Inhibition of caspase-9 through phosphorylation at Thr 125 by ERK MAPK. Nat Cell Biol 5: 647-654, 2003

42. Butterick TA, Nixon JP, Billington CJ, et al: Orexin A decreases lipid peroxidation and apoptosis in a novel hypothalamic cell model. Neurosci Lett 524: 30-34, 2012.

43. Tang J, Chen J, Ramanjaneya M, et al: The signaling profile of recombinant human orexin-2 receptor. Cell Signal 20: 1651-1661, 2008.

44. Danial NN and Korsmeyer SJ: Cell death: critical control points. Cell 116: 205-219, 2004.

45. Laburthe M, Voisin T and El Firar A: Orexins/hypocretins and orexin receptors in apoptosis: a mini-review. Acta Physiol 198: 393-402, 2010 